\title{
HISTOPATHOLOGICAL ANALYSIS OF SPLENECTOMY SPECIMENS IN A TERTIARY CARE HOSPITAL- A TWO-YEAR STUDY
}

\author{
Sudha Venkatesh ${ }^{1}$, Padmavathi Rajagopalan², Geetha Devadas ${ }^{3}$
}

1 Professor, Department of Pathology, Madras Medical College, Chennai, Tamilnadu, India.

${ }^{2}$ Professor, Department of Pathology, Madras Medical College, Chennai, Tamilnadu, India.

3Professor, Department of Pathology, Madras Medical College, Chennai, Tamilnadu, India.

\section{BACKGROUND}

ABSTRACT

Splenectomy is a rare surgical procedure performed worldwide. It is performed as an emergency procedure, especially in cases of traumatic injury and as an elective procedure for other causes. Apart from primary pathology involving spleen, splenectomy is performed for other disorders like pancreatitis and malignancy of stomach when secondary involvement of spleen is suspected. Haematologic disorders, both malignant and non-malignant, are other important indications for splenectomy. Worldwide studies have shown that trauma (45-75\%) is the leading cause of splenectomy in low income countries and during wars, while haematologic causes (20 - 35\%) account for majority of splenectomy in high income countries. Very few studies have been carried out in India, especially South India to analyse splenectomy causes and histomorphology.

Aim- This study is a two-year retrospective descriptive study done on splenectomy specimens received during September 2014 to August 2016 in the Pathology Department of Madras Medical College and Rajiv Gandhi Government General Hospital, Chennai. The aim of this study is to study the causes/ indications for splenectomy and to correlate the histomorphology with the clinical diagnosis.

\section{MATERIALS AND METHODS}

This is a retrospective descriptive study. All splenectomy specimens received during the two-year period from September 2014 to August 2016 were analysed. The splenectomy specimens were fixed in $10 \%$ buffered formalin, routinely processed and $\mathrm{H}$ and $\mathrm{E}$ sections were studied. Special stains and immunohistochemistry were done where necessary.

\section{RESULTS}

90 cases of splenectomy were received in the study period. The causes and indications varied widely. Most common cause was trauma causing laceration of the spleen (47) (52.2\%). Next cause was pancreatic pathology associated with splenomegaly (13) (14.4\%). Other causes were portal hypertension with splenomegaly (7) (7.8\%), hypersplenism (6) (6.7\%), hereditary spherocytos is (5) (5.6\%), splenic abscess (4) (4.5\%), splenic cyst (3) (3.3\%), (one of which turned out to be Lymphangioma of spleen), splenic artery pseudoaneurysm (3) (3.3\%) and one case each of carcinoma stomach and eventration of diaphragm.

\section{CONCLUSION}

Splenectomy is indicated in a wide spectrum of disorders. Histopathological examination and its clinical correlation is useful in the management of these cases. It helps to study the pathology of spleen in various disorders ranging from trauma, haematologic disorders, portal hypertension and primary splenic lesions. This study highlights the wide variety of lesions encountered in splenectomy specimens including very rare conditions like epithelial cyst and lymphangioma of spleen.

\section{KEY WORDS}

Splenectomy, Trauma, Hereditary Spherocytosis, Lymphangioma of Spleen, Epithelial Cyst of Spleen.

HOW TO CITE THIS ARTICLE: Venkatesh S, Rajagopalan P, Devadas G. Histopathological analysis of splenectomy specimens in a tertiary care hospital- a two-year study. J. Evolution Med. Dent. Sci. 2018;7(44):4794-4801, DOI: 10.14260/jemds/2018/1069

\section{BACKGROUND}

Spleen is the largest organ of the mononuclear phagocytic system and is involved in all systemic inflammations, haematopoietic disorders as well as metabolic disturbances. Splenectomy is performed for various indications, which include primary splenic pathology or splenomegaly due to metabolic and systemic diseases, haematologic disorders, trauma and malignancies.

'Financial or Other Competing Interest': None.

Submission 18-09-2018, Peer Review 14-10-2018,

Acceptance 20-10-2018, Published 29-10-2018.

Corresponding Author:

Dr. Sudha Venkatesh,

Professor, Department of Pathology,

Madras Medical College,

Chennai-600003,

Tamilnadu, India.

E-mail: sudha.astra@gmail.com

DOI: $10.14260 /$ jemds/2018/1069
The location of spleen in the abdomen where it is not protected by a bony cage makes it very prone to traumatic injury, especially in road traffic accidents.(1,2) Trauma is the main indication for emergency splenectomy. Other causes of splenic enlargement varies with geographic location. Chronic malaria could be a cause of splenomegaly in endemic areas. Haematologic disorders with splenic involvement like hereditary haemolytic anaemias, idiopathic immune thrombocytopenia result in splenomegaly and may require splenectomy.(3) Other disorders in which splenectomy is indicated include non-cirrhotic portal hypertension, pancreatic neoplasms, chronic calcific pancreatitis with portal hypertension and lesions in neighbouring organs. Primary splenic pathology for which splenectomy may be performed include abscess, cysts, sarcoidosis and tumours which are comparatively rare.

This study aims to highlight the histopathologic features in splenectomy specimens received in our centre and to correlate with clinical indications. The incidence, age and sex 


\begin{tabular}{|c|c|c|c|}
\hline 3 & Non-Cirrhotic Portal Hypertension & $\begin{array}{c}\text { CVC Spleen } \\
\text { One case also showed EMH and presented } \\
\text { clinically with Hypersplenism }\end{array}$ & 7 \\
\hline 4 & Hypersplenism & $\begin{array}{c}\text { CVC Spleen } \\
\text { EMH } \\
\text { One case with EMH also showed Infarct }\end{array}$ & $\begin{array}{l}4 \\
2\end{array}$ \\
\hline 5 & Hereditary Spherocytosis & $\begin{array}{c}\text { Congestion of Cords of Billroth, } \\
\text { haemosiderin laden macrophages } \\
\text { One case showed Infarct in addition }\end{array}$ & 5 \\
\hline 6 & Splenic Abscess & $\begin{array}{c}\text { Perisplenic Abscess } \\
\text { Tuberculous Abscess } \\
\text { Pyemic Abscess }\end{array}$ & $\begin{array}{l}1 \\
1 \\
2\end{array}$ \\
\hline 7 & Splenic Cyst & $\begin{array}{c}\text { Primary Epithelial Cyst } \\
\text { Lymphangioma of Spleen }\end{array}$ & $\begin{array}{l}2 \\
1\end{array}$ \\
\hline 8 & Splenic Artery Pseudoaneurysm & $\begin{array}{c}\text { CVC Spleen } \\
\text { Haematoma } \\
\text { Infarct + Perisplenic Abscess }\end{array}$ & $\begin{array}{l}1 \\
1 \\
1\end{array}$ \\
\hline 9 & Carcinoma Stomach & Congested Spleen & 1 \\
\hline 10 & Eventration of Diaphragm & Congested Spleen & 1 \\
\hline \multicolumn{4}{|c|}{ Table 3} \\
\hline
\end{tabular}

\section{Abbreviations}

CCP - Chronic Calcific Pancreatitis, PHT - Portal Hypertension, CVC - Chronic Venous Congestion, EMH - Extramedullary Haematopoiesis.

All the splenectomy specimens done for splenic injury showed laceration with some cases showing infarction (Fig. 2) and one case showed haematoma (Fig. 3). Among splenectomy done for pancreatic pathology, one showed pseudocyst of spleen, while one other showed perisplenic abscess. All the others showed features of congestion of spleen.

All the cases of non-cirrhotic portal hypertension showed features of chronic venous congestion of spleen with one showing extramedullary haematopoiesis (Fig. 4). In cases of hypersplenism, all showed chronic venous congestion with 2 of them showing features of extramedullary haematopoiesis and one showing foci of infarct as well.

All the cases of Hereditary Spherocytosis showed features of congestion with cords of Billroth filled with sequestered spherocytes, atrophy of white pulp, haemosiderin deposition and increased fibrous tissue. Out of the 4-splenectomy specimens received for abscess, one revealed the features of tuberculous abscess with caseation necrosis and multiple epithelioid granulomata with Langhans type of multinucleated giant cells (Fig. 5, 6). One case showed perisplenic abscess and the other 2 showed pyemic abscess (Fig. 7).

Among the 3 cases of splenic cysts, 2 were primary epithelial cyst of spleen composed of thin fibrocollagenous cyst wall lined by a single layer of flattened to cuboidal epithelium (Fig. 8, 9). One showed the features of lymphangioma of spleen. Grossly, multiple cysts of varying sizes was noted which was filled with pale whitish fluid material (Fig. 10, 11). Microscopically, multiple cystic spaces lined by flattened epithelium and containing eosinophilic fluid material (lymph) was noted (Fig. 12,13, 14).

In cases of splenic artery pseudoaneurysm, one case showed haematoma and rupture of spleen. Second one showed perisplenic abscess and infarct, while the third was congested spleen. Splenectomy done in case of carcinoma stomach and eventration of diaphragm showed congested spleen.

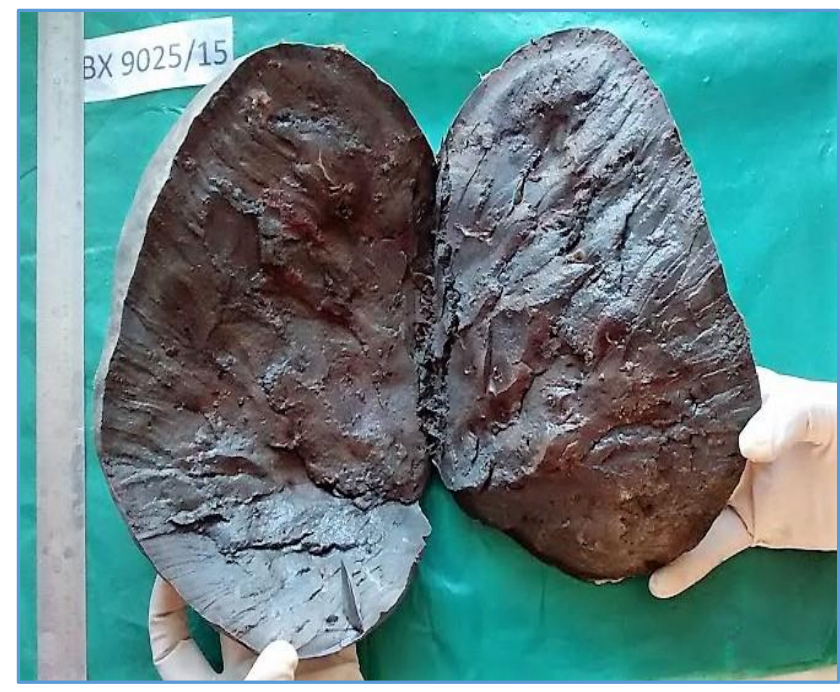

Figure 1. Hereditary Spherocytosis; Massive Splenomegaly

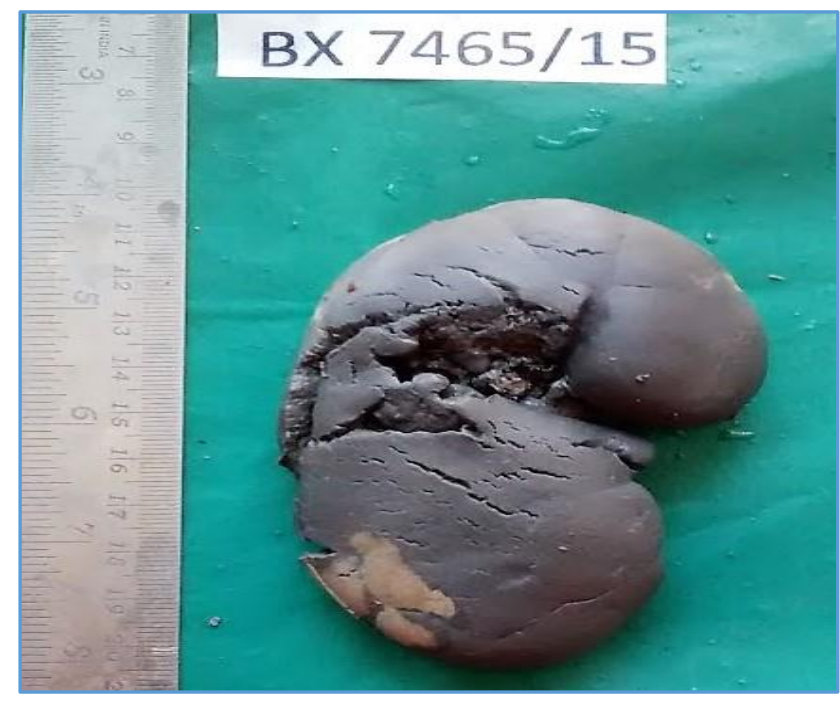

Figure 2. Grey White Infarct of Spleen 


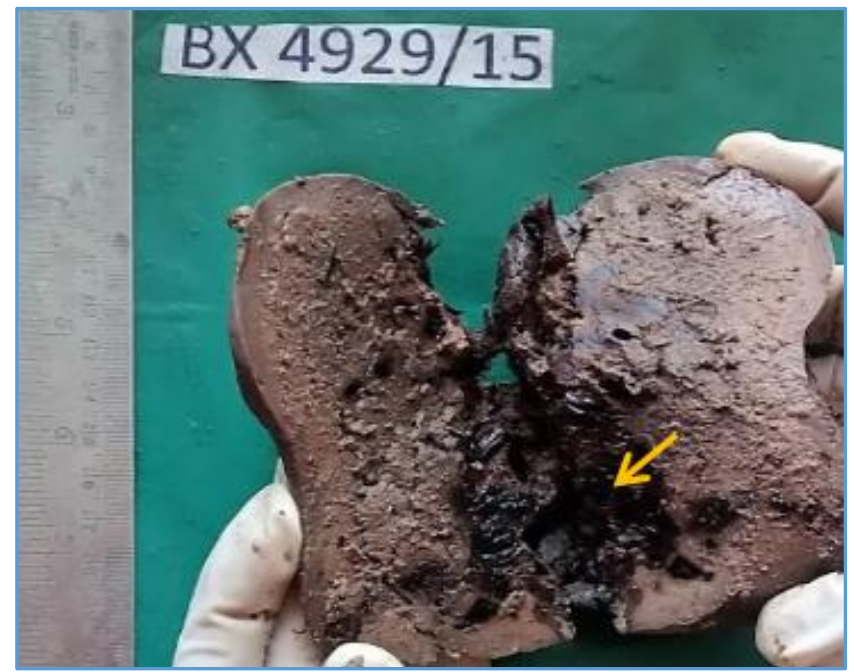

Figure 3. Spleen Laceration with Haematoma (Arrow)

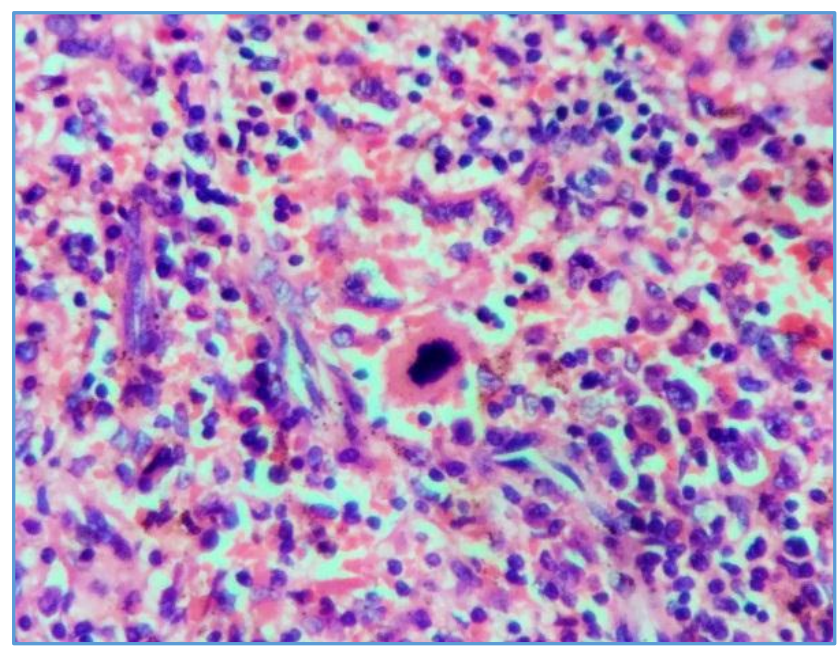

Figure 4. 40X H and E-EMH; Megakaryocyte with Haematopoietic Elements

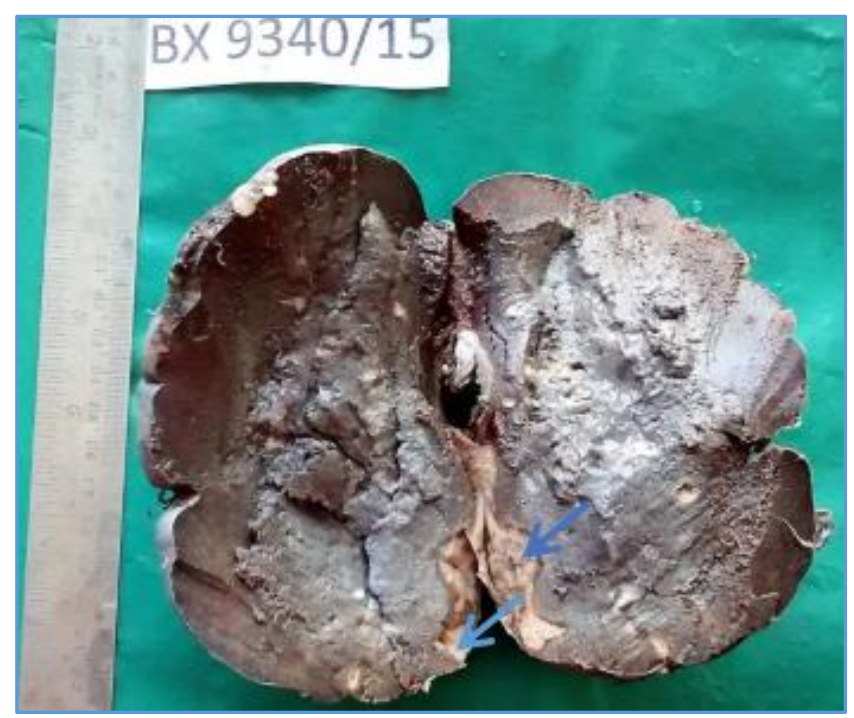

Figure 5. Spleen with Tuberculous Abscess (Arrows)

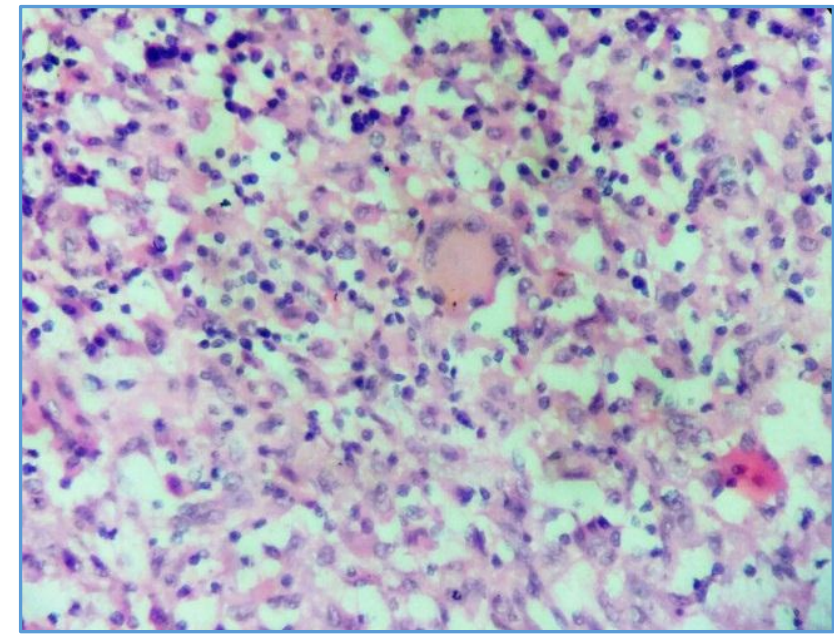

Figure 6. 40X H and E - Epithelioid Granuloma with Langhans Giant Cell; Tuberculous Abscess

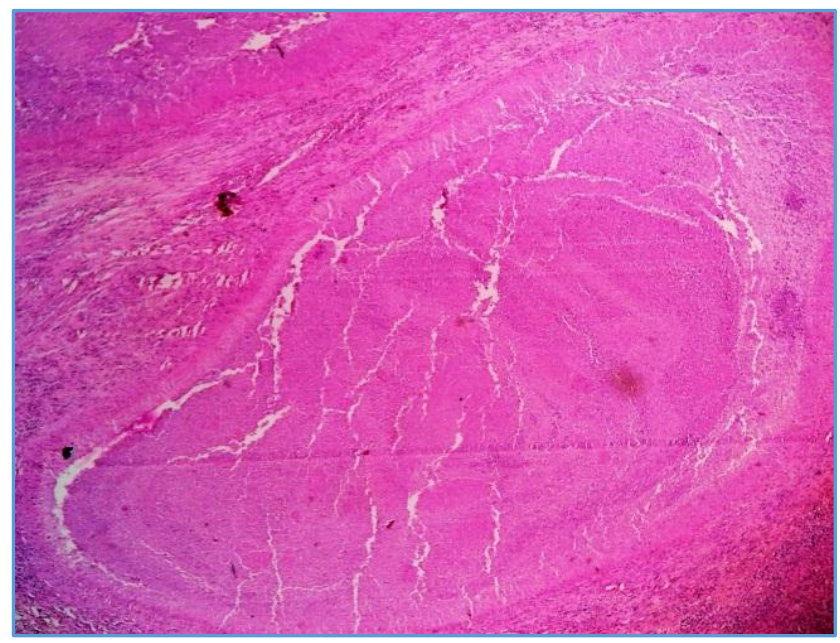

Figure 7. 10X H and E-Abscess with Necrotic Exudate

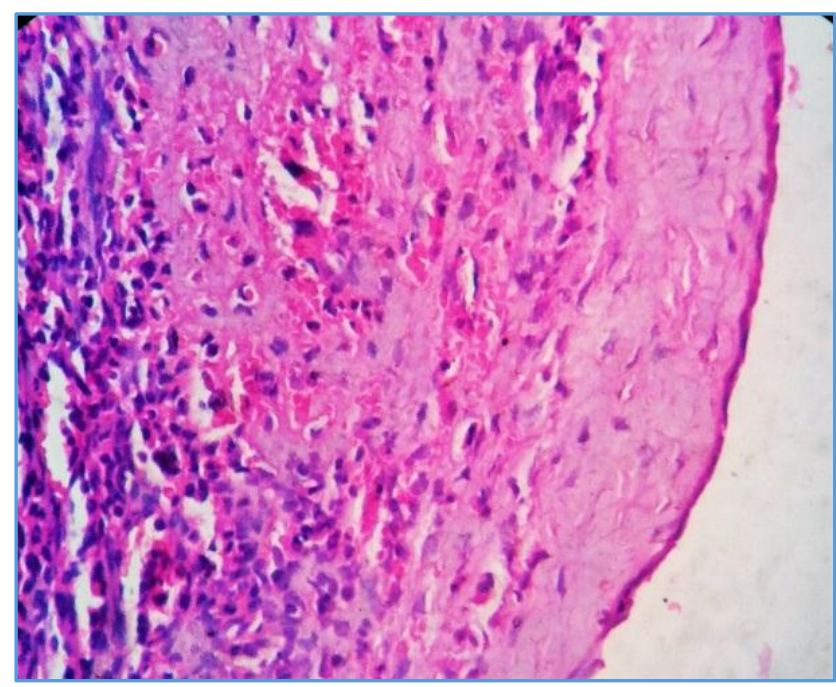

Figure 8. 40X H and E-Spleen with Cyst Wall Lined by Flattened Epithelial Cells 


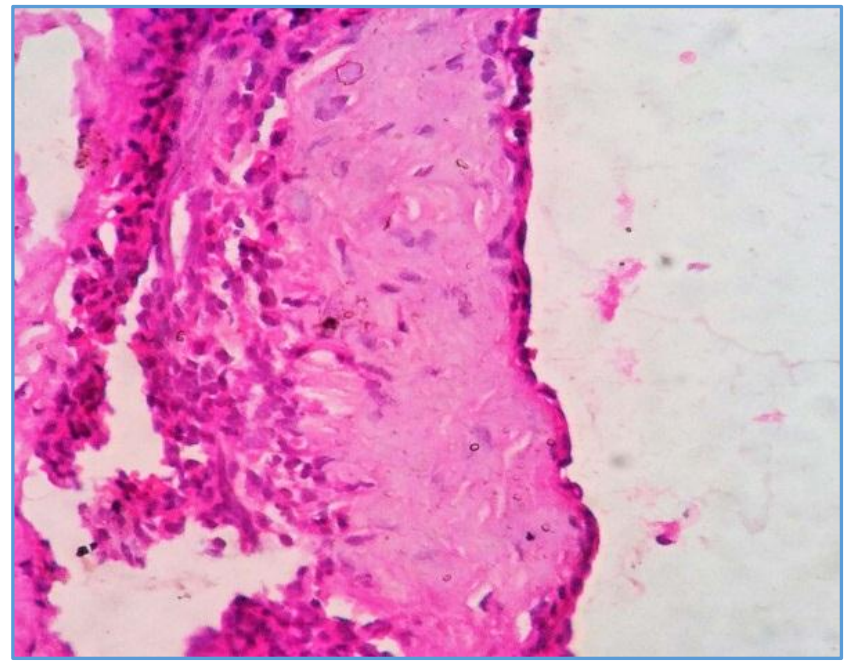

Figure 9. 40X H and E-Cyst Wall Lined by Flattened Epithelium; Epithelial Cyst

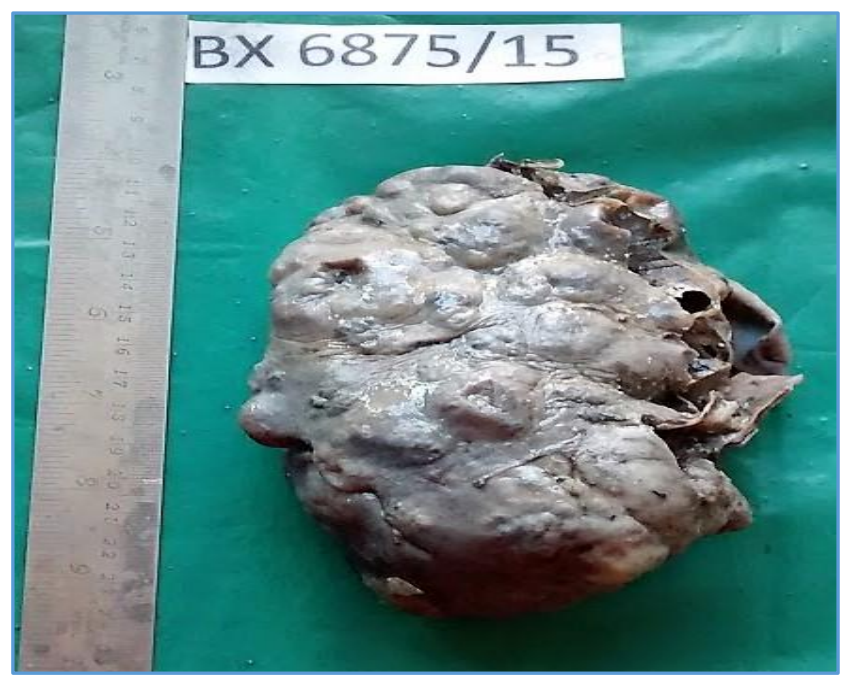

Figure 10. Spleen with Multiple Cysts

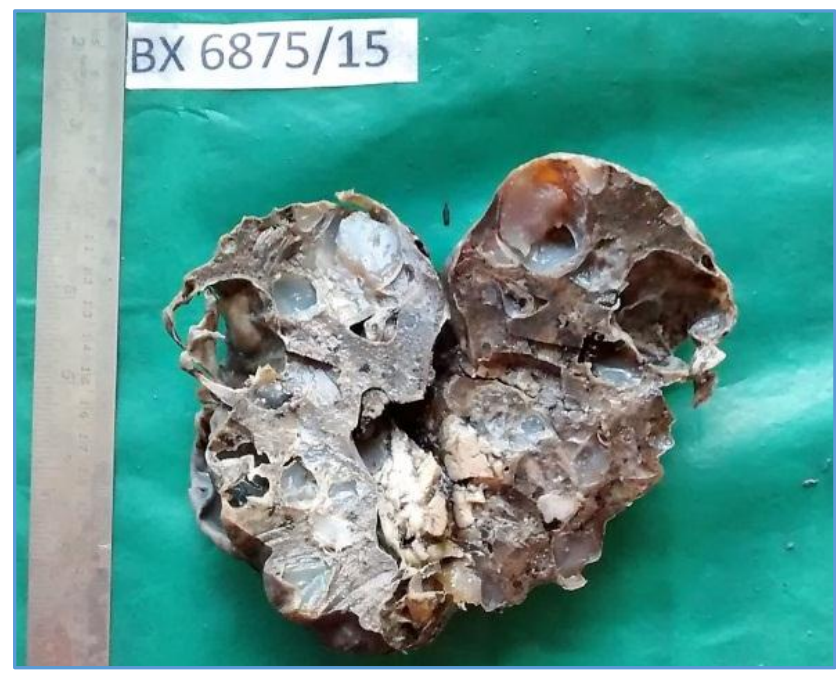

Figure 11. Spleen with Multiple Dilated and Cystic Spaces Filled with Whitish Material; Lymphangioma

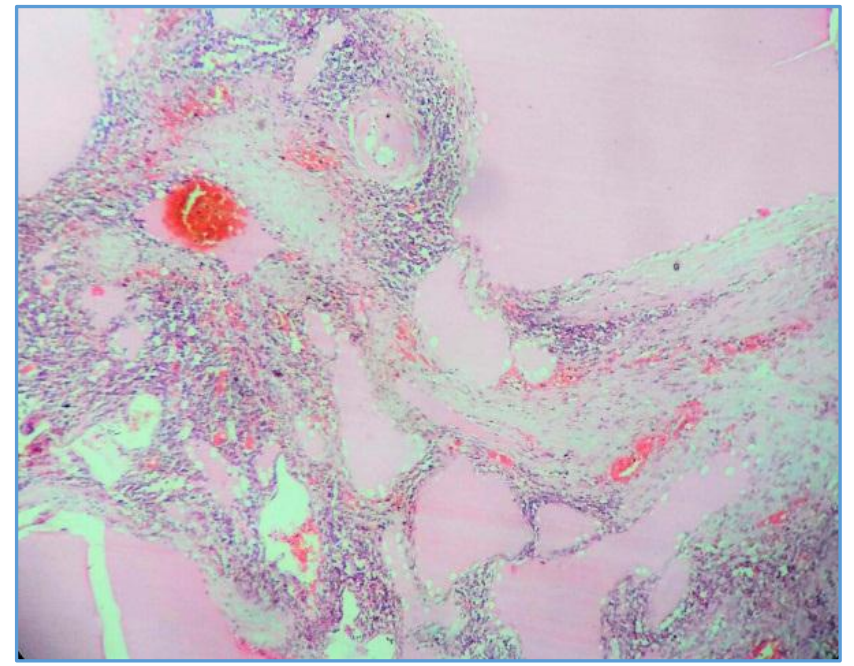

Figure 12. 10X H and E - Cystically Dilated Lymph Filled Spaces

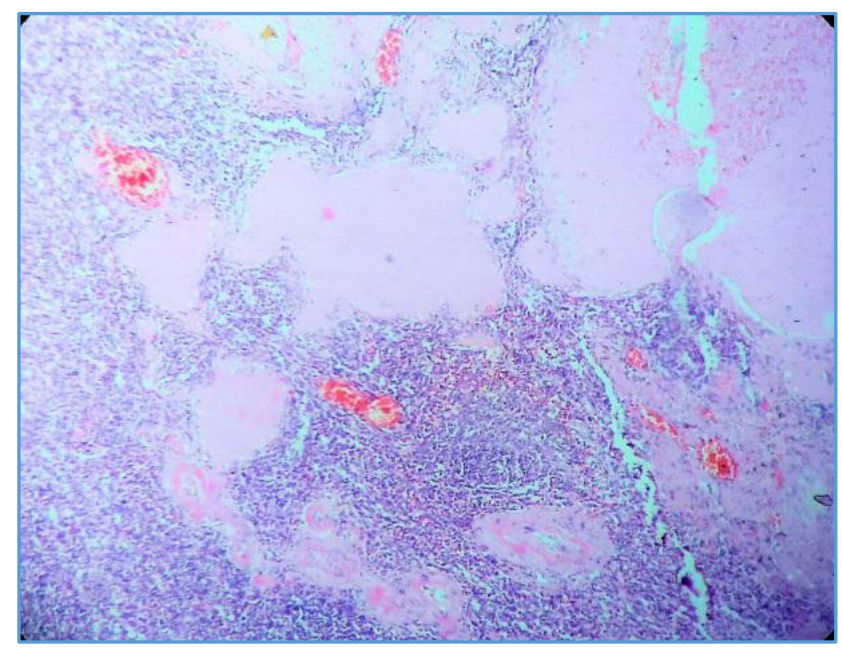

Figure 13. 10X H and E-Cystically Dilated Lymph Filled Spaces

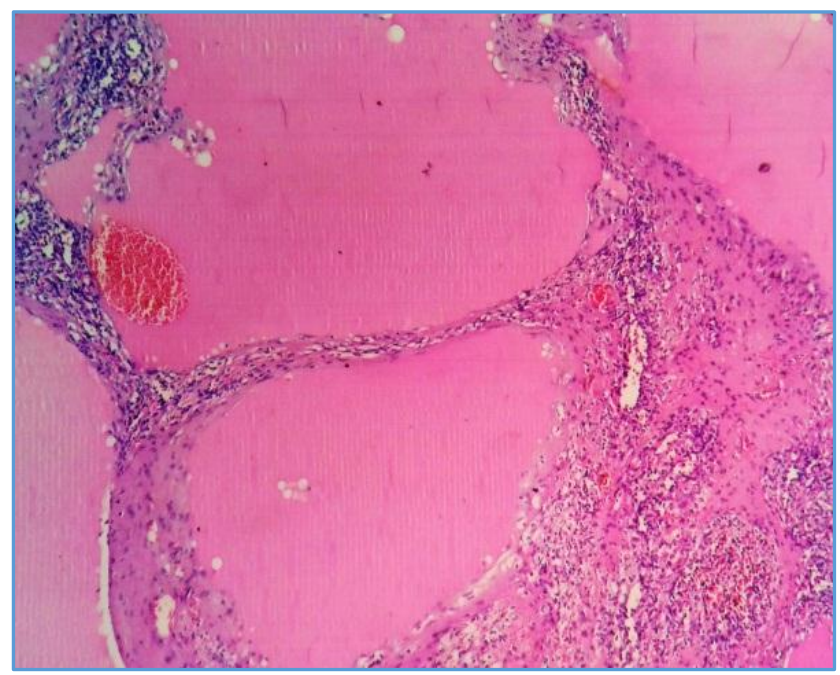

Figure 14. 40X H and E Dilated Spaces Lined by Flattened Cells - Lymphangioma 


\section{DISCUSSION}

Various studies worldwide have reported different proportion of splenectomy following trauma, varying from $15-75 \%$ in different countries. In high income countries like USA, Australia and European nations, splenectomy following traumatic injury is $15-30 \% .(4,5)$ In Iran, Khamechian(6) reported $75 \%$ of traumatic causes and Deodhar(7) from India reported similar results. In our study, trauma accounted for $52.2 \%$ of splenectomies. This correlates with other studies in which it was observed that in low income countries and during wars there was a higher incidence of splenectomy following traumatic injury. The reason for this could be that trauma, mainly road traffic accidents are more common in big metropolitan cities in India. Blunt injury and trauma causes laceration, capsular tear and intraperitoneal haemorrhage. Farhi et al found that germinal centres with an expanded marginal zone and other signs of lymphoid hyperplasia were seen more commonly in ruptured spleens than in controlled cases.(8) Similar results were reported by Barnard et al and van Krieken et al who found that when compared with controls, spleens with traumatic injury showed more white pulp and lymphoid tissue with alteration in the lymphocyte population in different compartments. $(9,10)$ In this study, no such significant lymphoid hyperplasia was observed. About onefourth of the injured spleens showed infarction in addition to the laceration and haemorrhage. Spleens which were moderately to severely enlarged showed features of congestion.

Congestive splenomegaly occurs due to chronic venous outflow obstruction which can be as a result of intrahepatic disorders, extrahepatic disorders or systemic venous congestion. Common causes include portal hypertension, which can be either due to cirrhosis or non-cirrhotic portal fibrosis. In Chinese and Asian population portal hypertension and hypersplenism secondary to cirrhosis is an important cause for splenectomy, ${ }^{(11,12)}$ ranging from 10 - 21\%. In similar Italian studies, portal hypertension does not appear to be a cause of splenectomy,(13) accounting for only $1-2 \%$. In this study, it accounted for $21 \%$ similar to that of other Asian and Chinese studies. Microscopically, it is characterised by marked dilation of veins and sinuses, atretic lymphoid follicles, haemosiderin laden macrophages and Gamna-Gandy bodies which are sclerosiderotic nodules. In this study, all the cases with portal hypertension and chronic pancreatitis associated with portal hypertension showed features of chronic venous congestion of spleen with some of them showing GamnaGandy bodies.

Among the non-traumatic splenectomy, haematologic indications vary in different countries and in different series. In American and British studies, haematologic malignancies $(20-52 \%)$ top the indications, while in Sweden it is ITP and in Asia and Africa it is haemoglobin disorders.(14,15,16) This may be due to the fact that in endemic areas of malaria, haemoglobin abnormalities may give some protection and hence haemoglobin disorders are more prevalent in Africa and parts of Asia. Splenectomy for non-malignant haematologic disorders varies from 9 - 35\% in different studies in different parts of the world. In a study from North-Eastern part of India, which is a thalassemic belt $40 \%$ of non-malignant haematologic indications for splenectomy was thalassemia.(17) This correlated with another Indian study in paediatric age group.(18) Another study from South India reported 18\% of hereditary spherocytosis and $9 \%$ of thalassemia leading to splenectomy.(19) In our study, Hereditary Spherocytosis was the only haematologic disorder encountered as a cause for splenectomy accounting for $5.6 \%$. Hereditary spherocytosis is associated with moderate-to-massive splenomegaly. Microscopically, spleen shows congestion of cords of Billroth and increased number of phagocytes. Sinusoids may appear empty, because of the presence of ghost RBCs. Haemosiderin deposition and foci of infarct may be seen. In our study, all cases of hereditary spherocytosis showed massive congestion of cords of Billroth with increased phagocytosis and one case showed infarct which correlates with other studies.

Extramedullary Haematopoiesis (EMH) can occur in spleen in both neoplastic and non-neoplastic conditions. Haematologic neoplasms, both myeloid and lymphoid may be associated with EMH in spleen. Among the non-neoplastic conditions autoimmune haemolytic anaemia, TTP and other conditions predominate.(20) In this study, EMH was observed in patients who presented with hypersplenism. JB Sundaresan et al reported that $60 \%$ of patients of hypersplenism had splenomegaly of congestive origin due to cirrhotic or noncirrhotic portal hypertension, 7\% were of idiopathic origin.(21) In our study one case was due to portal hypertension, (33\%) while the other cases were idiopathic (67\%).

Splenic abscess is rare and incidence varies in different series. Autopsy series have placed the incidence of splenic abscess at $0.2-0.07 \% .(22,23)$ In Denmark, the incidence is $0.05 \%$ per 1000 hospital discharges per year. The incidence of splenectomy for splenic abscess is decreasing, because of the advances in health and hygienic practices in the Western world. In India, a few cases of tuberculous abscess in immunocompetent hosts has been reported.(24) In adults, splenic abscess is usually solitary.(25) In this study, all 3 cases showed multiple abscesses. The most common aetiology is haematogenous spread from infection elsewhere in the body. The infectious agents could be bacterial, fungal or mycobacterium tuberculosis.(26) In this study, one case revealed tuberculous abscess which was confirmed by AFB staining for tubercle bacilli. Tuberculous abscess, though more common in immunocompromised host, can also occur in immunocompetent patients. In this study, the patient was not immunocompromised. Two cases showed multiple abscesses, which were suppurative in nature. One case showed perisplenic abscess with predominant involvement of capsular and extracapsular foci. There was no history of trauma in this case. Another case of perisplenic abscess had a ruptured pseudoaneurysm of splenic artery.

Splenic cysts are very rare with an incidence of $0.07 \%$.(27) So far about 800 cases only have been reported in literature. They were classified by Martin as primary or true cysts and secondary or pseudocysts.(28) Pseudocysts form 75\% of nonparasitic cysts of spleen.(29) They do not have an epithelial lining. Cyst wall is composed of dense fibrous tissue. They occur secondary to trauma, infection or infarction. In our study we came across one case of pseudocyst of spleen, which was secondary to chronic calcific pancreatitis. Primary cysts are seen mostly in children and young adults. They are usually solitary and show a lining of columnar, cuboidal or squamous cells. In this study 2 cases of primary epithelial cysts (3\%) were identified, both of which were solitary and had a flattened-to-cuboidal lining. Golmohammadzadeh et al in their 
study reported $6.25 \%$ of pseudocyst and $26.6 \%$ of epithelial cyst.(30)

Lymphangioma of spleen is a relatively rare benign neoplasm, which corresponds to malformation of the lymphoid system. It constitutes $<1 \%$ of lymphangiomas. The first case was reported in 1885 by Frink.(31) Obstruction or agenesis of the lymphatic system results in lymphangiectasia leading to formation of lymphangioma. Though most cases are seen in children, a few cases have been reported in adults.(32) Lymphangioma may be subcapsular or may involve the entire organ.(33) They are most often of cavernous type, other types being capillary and macrocystic. Immunohistochemically, they are positive for CD31, CD34, Factor VIII related antigen and negative for keratin and mesothelial markers.(34) So far less than 200 cases have been reported in the literature. In this study, one case of lymphangioma of spleen was identified in a 48-year-old female patient. Clinically and radiologically, a diagnosis of splenic cyst was made in this patient. Grossly, spleen showed a lesion consisting of multiple cystic spaces of varying sizes filled with pale whitish fluid material. Microscopically, it showed the features of lymphangioma of cavernous type. Immunohistochemistry showed positive staining for CD31 and CD34 and was negative for cytokeratin and calretinin.

\section{CONCLUSION}

This study highlights the fact that splenectomy, though a rare procedure, is performed for a variety of conditions. The most common indication in this study was traumatic injury of spleen. Portal hypertension due to hepatic and non-hepatic causes constituted the second most common indication. Primary lesions of spleen are rare and most of them are benign. Rare lesions like lymphangioma of spleen have been reported in this study. The histopathologic examination and its clinical correlation are useful in the management of these cases, especially tuberculous abscess where specific therapy has to be administered. To conclude, this study helps to understand the pathology of spleen in various disorders including trauma, haematologic disorders, portal hypertension and primary splenic lesions which are rare like cysts and lymphangioma of spleen.

\section{REFERENCES}

[1] Ameh EA, Chirdan LB, Nmadu PT. Blunt abdominal trauma in children: epidemiology, management and management problems in a developing country. Padiatr Surg Int 2000;16(7):505-9.

[2] AL-Kindi H, DeviL, George M. Splenic pathology in traumatic rupture of the spleen: a five year study. Oman Med J 2009;24(2):81-3.

[3] Browning MG, Bullen N, Nokes T, et al. The evolving indications for splenectomy. $\mathrm{Br} \mathrm{J}$ Haematol 2017;177(2):321-24.

[4] Thomsen RW, Schoonen WM, Farkas DK, et al. Risk for hospital contact with infection in patients with splenectomy: a population-based cohort study. Ann Intern Med 2009;151(8):546-55.

[5] Edgren G, Almqvist R, Hartman M, et al. Splenectomy and the risk of sepsis: a population based cohort study. Ann Surg 2014;260(6):1081-7.
[6] Khamechian T, Alizargar J, Farzanegan M. Pattern of splenectomy indications in Kashan shahid-beheshti hospital: a 5 year study. Arch Trauma Res 2013;1(4):180-3.

[7] Deodhar M, Kakkar N. An audit of splenectomies in a teaching hospital in North India. Are postsplenectomy guidelines being complied with? J Clin Pathol 2004;57(4):407-10.

[8] Farhi DC, Ashfaq R. Splenic pathology after traumatic injury. Am J Clin Pathol 1996;105(4):474-8.

[9] Barnard H, Dreef EJ, van Krieken JH. The ruptured spleen. A histological, morphometrical and immunohistochemical study. Histol Histopathol 1990;5(3):299-304.

[10] van Krieken JH, te Velde J, Hermans J, et al. The amount of white pulp in the spleen; a morphometrical study done in methacrylate-embedded splenectomy specimens. Histopathology 1983;7(5):767-82.

[11] Wang X, Li Y, Crook N, et al. Laparoscopic splenectomy: a surgeon's experience of 302 patients with analysis of postoperative complications. Surg Endosc 2013;27(10):3564-71.

[12] Hayashi H, Beppu T, Shirabe K, et al. Management of thrombocytopenia due to liver cirrhosis: a review. World J Gasteroenterol 2014;20(10):2595-605.

[13] Casaccia M, Torelli P, Pasa A, et al. Putative predictive parameters for the outcome of laparoscopic splenectomy: a multicultural analysis performed on the Italian Registry of laparoscopic surgery of spleen. Ann Surg 2010;25(2):287-91.

[14] Bickenbach KA, Gonen M, Labow DM, et al. Indications for and efficacy of splenectomy for haematological disorders. Br J Surg 2013;100(6):794-800.

[15] Machado NO, Grant CS, Alkinch S, et al. Splenectomy for haematological disorders: a single centre study in 150 patients from Oman. Int J Surg 2009;7(5):476-81.

[16] Bagrodia N, Button AM, Spanheimer PM, et al. Morbidity and mortality following elective splenectomy for benign and malignant hematologic conditions: analysis of the American college of surgeons national surgical quality improvement Program data. JAMA Surg 2014;149(10):1022-9.

[17] Sarangathem B, Pukhrambam GD, Laishram S, et al. Histomorphological pattern of splenectomy specimens: a five year study in a tertiary teaching hospital. IOSRJDMS 2014;13(1):40-3.

[18] Ramani M, Ranganath D, Husain KW, et al. A histopathological review of splenectomies in haematological disorders in paediatric age. J Evol Med Dent Sci 2013;12(28):5088-99.

[19] D'Souza C, Rajan J, Pai PK. Analysing the clinical and pathological aspects of splenectomy specimens. Int J Biomed Res 2014;5(2):132-5.

[20] O'Malley DP, Kim YS, Perkins SL, et al. Morphologic and immunohistochemical evaluation of splenic haematopoietic proliferations in neoplastic and benign disorders. Mod Pathol 2005;18(12):1550-61.

[21] Sundaresan JB, Dutta TK, Badrinath S, et al. Study of hypersplenism and effect of splenectomy on patients with hypersplenism. J Ind Acad Clin Med 2005;6(4):291-6. 
[22] Sarr MG, Zuidema GD. Splenic abscess--presentation, diagnosis and treatment. Surgery 1982;92(3):480-5.

[23] Chulay JD, Lankerani MR. Splenic abscess. Report of 10 cases and review of literature. Am J Med 1976;61(4):513-22.

[24] Mitra S, Mitra M, Sahoo S, et al. Tubercular splenic abscess: two case reports with review of literature. J Asso Chest Phy 2015;3(2):69-72.

[25] Faught WE, Gilbertson JJ, Nelson EW. Splenic abscess: presentation, treatment options and results. Am J Surg 1989;158(6):612-4.

[26] Mustafa M, Menon J, Muniandy RK, et al. Splenic abscess: etiology, clinical spectrum and therapy. IOSR J Pharm 2015;5(1):37-41.

[27] Ingle SB, Hinge Ingle CR, Patrike S. Epithelial cysts of spleen: a mini-review. World J Gastroenterol 2014;20(38):13899-903.

[28] Martin JW. Congenital splenic cysts. Am J Surg 1958,96(2):302-8.
[29] Garvin DF, King FM. Cysts and nonlymphomatous tumors of the spleen. Pathol Annu 1981;16 Pt 1:61-80.

[30] Golmohammadzadeh H, Maddah G, Hojjati YS, et al. Spenic cysts: analysis of 16 cases. Caspian J Intern Med 2016;7(3):217-21.

[31] Solomon EG, Patriarheas GV, Mpadra FA, et al. Asymptomatic adult cystic lymphangioma of the spleen: case report and review of literature. Magn Reson Imaging 2003;21(1):81-4.

[32] Ioannidis I, Kahn AG. Splenic lymphangioma. Arch Pathol Lab Med 2015;139(2):278-82.

[33] Schmid C, Beham A, Uranus S, et al. Non-systemic diffuse lymphangiomatosis of spleen and liver. Histopathology 1991;18(5):478-80.

[34] Marymont JH, Gross S. Patterns of metastatic cancer in the spleen. Am J Clin Pathol 1963;40:58-66. 